\title{
Para além da lei Agonismo como princípio de ação dos movimentos sociais
}

\section{Daniel de Mendonça ${ }^{l}$}

\section{Introdução}

São direitos dos trabalhadores urbanos e rurais, além de outros que visem a melhoria de sua condição social: salário mínimo, fixado em lei (...), capaz de atender as suas necessidades vitais básicas e às de sua família com moradia, alimentação, educação, saúde, lazer, vestuário, higiene, transporte e previdência social, com reajustes periódicos que lhe preservem o poder aquisitivo, sendo vedada sua vinculação para qualquer fim (Art. 7 ; IV, Constituição Federal de 1988).

Esta epígrafe dá conta do irrealizável. Denuncia a ineficácia e a hipocrisia do texto da lei; contudo é incapaz de apontar os hipócritas. Estes não são os deputados, os constituintes, os governantes, a direita ou a esquerda. Os hipócritas estão num local secreto, escondidos no tempo. São os que acreditaram e fizeram acreditar na universalidade do texto legal, na abrangência territorial do direito. Aqueles mesmos que também um dia afirmaram que o desconhecimento da lei era inescusável a qualquer cidadão, seja qual for a sua história de vida. São ainda os mesmos que obrigam todos a obedecer e executar os mandamentos das

1 Jurista, doutorando em Ciência Política pela UFRGS. Endereço: ddmendonca@bol.com.br 
leis, sob pena de infringirem outras leis, aquelas que punem os que não obedecem ou não executam os mandamentos legais. O sistema jurídico, assim, como no movimento de um compasso, termina onde começou sua tautológica auto-referência.

De uma parte, o fato trivial é que - mesmo sendo o direito cego às questões sociais quando leva "ao pé da letra" o mandamento da lei positiva - as leis têm aplicação social. De nada adianta enunciar o fim da miséria, ou o início da prosperidade num texto legal, sem que se tenha meios efetivos em termos de políticas públicas para a erradicação efetiva da pobreza. A lei, antes de ser lei e ter alguma eficácia jurídica, deve ser vista como um ato de vontade política de políticos e não de juristas. E um ato de vontade política nem sempre é realizável, seja pela demagogia, seja impossibilidade material da concretização do direito enunciado.

De outra parte, movimentos sociais têm continuamente lutado em todo o mundo pelo reconhecimento - e não pela mera tolerância - de suas demandas específicas. Mulheres, por direitos civis e sociais iguais aos homens; negros buscando reconhecimento em relação aos brancos; homossexuais, em relação aos heterossexuais; pobres, em relação aos ricos; enfim, o particular quer, cada vez mais, ampliar seus conteúdos específicos e se tornar universal. O meio conhecido, e mais reconhecido, de conquistas políticas por grupos sociais é a tradução de suas demandas específicas em texto de lei. Acreditam que assim conseguem avançar em sua luta por reconhecimento identitário. Em muitos casos, efetivamente, os direitos são alargados. Contudo, em outros casos, a lei torna-se mesmo uma letra morta: direitos são ao mesmo tempo enunciados e, pelo descumprimento legal, são jogados no porão do esquecimento.

Dessa forma, é certamente um sonho ingênuo de alguns movimentos sociais a idéia de que suas lutas identitárias terminam quando uma lei que assegura determinado direito particular é publicada. A publicação de um texto legal constituidor de direito específico para qualquer identidade não é em absoluto suficiente para dar seu reconhecimento, nem no direito específico, tão pouco como uma diferença social constituída.

Este status universalizante que goza a lei pode servir, na democracia representativa contemporânea, apenas como um instrumento de tolerância de identidades. Em outras palavras, o universal, representado pelo Estado, em muitos momentos, pode não estar efetivamente reconhecendo as "minorias", mas ape- 
nas tolerando-as. Este status legal pode servir ainda para conformar movimentos sociais e tal acomodação é uma das causas do contínuo processo de dominação a que estão submetidas as tão conhecidas "minorias".

Portanto, considerando a não rara possibilidade da impossibilidade do efetivo reconhecimento de grupos sociais simplesmente pela edição de um texto legal constituidor de direitos, os objetivos deste artigo são basicamente dois: 1) afirmar que a lei pode servir como um instrumento para a simples conformação de movimentos sociais; 2) propor que as lutas dos movimentos sociais devem constantemente apontar para duas questões centrais: uma mobilização interna em cada organização social para mantê-la unida e atuante e uma constante fiscalização do real implemento pelo Poder Público das demandas sociais transformadas em lei.

Tendo em vista nossos dois objetivos propostos, pretendemos realizar um exercício de problematização. Buscaremos defender que a positividade da lei pode muito bem transformar-se numa vitória de Pirro para um movimento social. Assim, na primeira parte deste artigo, analisaremos algumas razões possíveis da ineficácia do texto da lei, que pode acabar por transformar-se numa letra morta em termos de efetivas conquistas políticas por movimentos sociais. Na segunda parte, apresentaremos a noção de agonismo no contexto da Teoria do Discurso de Ernesto Laclau e Chantal Mouffe. Por fim, analisaremos a utilidade dessa categoria teórica como princípio de ações políticas por parte de movimentos sociais.

\section{Os direitos civis e sociais abstratos: a possibilidade da ineficácia da letra da lei}

A lei é um mandamento universal. Universal, pois - além da possibilidade desta atingir, pelo menos abstratamente, todos os membros de uma comunidade política e jurídica - uma vez publicada e posta em vigência, ela não pode, ou não poderia, ser contestada no que tange à sua aplicabilidade. Ninguém tem o direito de argumentar, por exemplo, que não cumpriu determinado mandamento da lei por desconhecê-lo. No artigo $3^{\circ}$ da Lei de Introdução ao Código Civil (Decreto-Lei ${ }^{\circ} 4.657$, de 4 de setembro de 1942), de forma tautológica ao sistema do Direito, a própria lei não perdoa o desconhecimento do corpo de leis ao estatuir que "ninguém se escusa de cumprir a lei, alegando que não a conhece". A 
lei, portanto, precisa ter um caráter universalizante. Necessariamente. Além disso, precisa conter em si uma possibilidade clara de sanção, de punição, pois, do contrário, seu descumprimento passará incólume. Sem esses requisitos - universalidade e sanção - não há porque falarmos de lei como instrumento regulador e instituidor de limites sociais.

Essa universalidade da lei virou, por todas essas razões já elencadas, objeto de desejo e por que não dizer, até mesmo de fetiche, por parte de movimentos sociais. Estes, certos de que, num estado democrático de direito, uma das formas mais eficazes de universalizar seus conteúdos específicos (demandas identitárias) é transformá-los em letra de lei. Esse ato de traduzir suas lutas particulares num diploma legal tem como resultado o reconhecimento formal por parte do Estado da existência desse movimento social e da universalização de parte de suas demandas de grupo. Tal estratégia está correta se a tomarmos hipoteticamente como se toma o mandamento da lei. Contudo, nem sempre o imperativo legal é cumprido e o direito acaba por não ser efetivado faticamente.

A não observância da lei, assim como ela própria, é um fato social. Apesar do sistema jurídico obrigar o cumprimento da legislação vigente, sabemos, por exemplo, que a epígrafe deste artigo - a qual estatui a capacidade do salário mínimo de atender as necessidades básicas do trabalhador e de sua família - é somente um de tantos mandamentos legais irrealizáveis do sistema jurídico brasileiro. Dessa forma, diante desse paradoxo, ou seja, da obrigatoriedade da aplicação da lei e de seu flagrante descumprimento, cabe-nos elencar alguns aspectos explicativos desse não cumprimento. Ao propor essa problematização, sabemos que aqui entramos talvez num dos terrenos mais delicados do campo jurídico e que nem de perto pretendemos esgotar o assunto.

Assim, acerca de algumas explicações desse flagrante não cumprimento de incontáveis mandamentos legais, partamos da idéia de que a expressão da lei ao contrário de uma posição de origem rousseauniana que infere sua existência como vontade da maioria - é a expressão de uma minoria, no sentido de que a vontade original de toda lei é antes a vontade de um grupo particular. Nesse sentido, por exemplo, uma lei municipal que obrigue o rebaixamento de calçadas e implantação de rampas em órgãos públicos e privados é uma norma fruto de um interesse originário de um grupo de pessoas portadoras de necessidades especiais. Mesmo uma lei que institui determinado imposto tem, ainda sim, na sua origem, a vontade de um grupo particular: aquele que está con- 
tingencialmente administrando o Estado. A lei, portanto, representa inicialmente a expressão de vontade de uma particularidade. Contudo, não podemos perder de vista a pretensão universalizante que reveste qualquer norma jurídica.

Pretensão é um direito suposto, uma ambição, um desejo, mas não é de per si a expressão da universalidade. Poderíamos fragilmente argumentar que o sistema legal - como a idéia do conjunto de toda legislação existente - possui um sentido universalizante, ou seja, os cidadãos grosso modo entendem genericamente que "as leis" devem ser respeitadas. Entretanto, tal argumento torna-se frágil no momento em que não raras vezes flagramos que as leis, tomadas individualmente, são desrespeitadas, ou cumpridas de forma precária. Não queremos com isso denunciar leis que não são cumpridas como quem ingenuamente busca seus necessários cumprimentos. Nem queremos, de outra forma, tão igualmente ingênua quanto anárquica, professar o não cumprimento de leis. Nossa intenção, para além disso, é discutir que a maior barreira que uma lei possui para seu cumprimento é conseguir faticamente universalizar o máximo possível seus conteúdos. Isso significa inicialmente partirmos do pressuposto de que a norma jurídica, em geral, possui um fraco vínculo social e tal fraqueza é certamente um dos principais motivos de sua não observância.

O referido fraco vínculo social deve ser entendido da seguinte forma. Já vimos que a vontade política que origina o texto legal é produto de um determinado grupo social (movimento social, partido político, governo). Essa vontade política, que tomamos por identitária, antes de transformar-se efetivamente em texto de lei, precisa necessariamente enfrentar um complexo processo legislativo cujo resultado é imprevisível. É assim que o ato da publicação e da vigência de uma norma é antecedido por um projeto de lei, discutido e aprovado no parlamento (após um moroso processo de análise em determinadas comissões especiais dependendo da matéria), sancionado ou vetado pelo poder executivo. Se sancionado pelo poder executivo, projeto transforma-se em lei após a publicação pelo chefe do executivo. Se vetado, este retorna ao parlamento que, em nova votação, decide se mantém ou não o veto. Se derrubado o veto do executivo, a lei é publicada pelo presidente da casa legislativa. Não conformado com a derrubada do veto, o chefe do poder executivo pode ainda ingressar com uma Ação Direta de Inconstitucionalidade, visando, via judiciário, cessar os efeitos da lei aprovada contra a sua vontade política. 
No decorrer desse moroso processo legislativo, não raras vezes o projeto de lei original sofre emendas, muitas vezes incorporadas como moeda de troca entre parlamentares ou até mesmo entre os poderes legislativo e executivo. O processo político de tramitação de leis é dotado de instabilidade e de imprevisibilidade, tanto em relação à possibilidade de aprovação do projeto de lei, como em que momento isso ocorrerá. Dessa forma, no caso de um movimento social que demandou originalmente determinado direito que se traduziu num projeto de lei, este torna-se em boa parte - não estamos aqui nos esquecendo da possibilidade da formação de lobbies - dependente do resultado do processo legislativo. Essa engenharia política do processo legislativo demonstra com nitidez o caráter nada natural de uma lei em relação a sua proposição inicial; antes, esta é uma construção artificial cujos agentes que participam de sua formulação vão muito além de um movimento social que demanda um direito.

Aprovada a lei, mesmo assim esta pode estar sujeita ainda a novos enfrentamentos políticos. Isso porque a constituição de um direito requer, ao mesmo tempo, a estipulação de um dever. Nesse ponto é que a pretendida universalidade da norma jurídica também não raras vezes é ameaçada. A disputa entre aqueles que detêm o direito e aqueles a quem é exigido o dever do cumprimento do mandamento legal abre a discussão de um assunto que não deveria ser, a rigor, no sentido de um sistema jurídico positivista, discutido. $\mathrm{O}$ famoso brocardo jurídico "a lei é dura, mas é lei” nem sempre tem aplicabilidade fática, pois a aplicação da lei é, além de uma regra jurídica, uma constante luta entre agentes políti$\cos$.

Nesse ponto, voltamos à questão do fraco vínculo social da norma jurídica. Como vimos, o sistema do direito pretende a universalização das leis, ainda que artificialmente. Se estivéssemos diante de um sistema de proposição e elaboração legal no sentido rosseauniano (o que não é o que aqui estamos propondo como solução!), a "vontade comum" seria a expressão da letra da lei. Nesse sentido, o vínculo social entre lei, "vontade" e "bem" comuns estaria assegurado. Não obstante, estamos diante de um regime político democrático representativo, no qual a vontade do representante (quem efetivamente vota a lei) não é em absoluto a vontade do representado. Aliás, como também já apontamos, nem o produto final da lei é a expressão exclusiva da vontade do parlamentar que propôs determinado projeto legislativo, uma vez que tal proposição sofre toda a sorte de intempéries durante sua tramitação. 
Sem este efetivo vínculo social, a lei entra em vigor concedendo direitos a uns e exigindo deveres de outros. Nesse ponto, entra-se num novo embate: o da aplicação da lei que, dependendo dos agentes que são atingidos por seu mandamento, fica de complicada satisfação. Tal complicada satisfação pode ser ainda acrescida do fato de que, sendo uma determinada norma que os próprios agentes do poder público não elejam como prioritária, estes acabam por não realizar uma fiscalização efetiva de seu cumprimento.

\section{Agonismo como categoria da teoria do discurso}

O possível descumprimento da norma jurídica por parte daqueles que teriam por dever cumpri-la, bem como a ausência de fiscalização do Estado para a efetivação dos direitos por ela enunciados, são causas suficientes e necessárias para que a lei torne-se uma letra morta. No caso particular dos movimentos sociais, por óbvio, uma lei ineficaz em nada faz avançar seus direitos identitários. Pelo contrário: esta pode ainda servir como fator desmobilizador de grupos sociais que podem ver todo seu esforço para a proposição de uma lei ter sido em vão em função de sua não aplicabilidade após sua publicação. Uma lei somente tem sentido se realmente constituir direitos. Desta forma, a fiscalização e a contínua mobilização de movimentos sociais em busca da satisfação efetiva de direitos conquistados são fundamentais para a sua manutenção como grupos identitários, bem como para a radicalização do processo democrático. É nesse particular que entendemos importante lançarmos mão da noção de agonismo como princípio de ação de movimentos sociais em busca de maior reconhecimento.

A noção de agonismo empregada neste artigo tem seu locus teórico e epistemológico na Teoria do Discurso de Ernesto Laclau e Chantal Mouffe. Tal noção, segundo Mouffe (2000), foi incorporada a esta corrente teórica para complexificar outra noção, a de antagonismo, utilizada em diversos trabalhos destes autores e cuja diferenciação faremos a seguir. Antes de propriamente apresentarmos os principais elementos constituidores da noção de agonismo, entendemos importante situá-la no contexto geral da Teoria do Discurso, indicando, ainda, a potencialidade analítica que esse projeto teórico possui para a temática dos movimentos sociais.

Dessa forma, em relação à Teoria do Discurso, é importante inicialmente destacarmos que qualquer análise acerca de movimentos sociais deve levar em 
consideração um universo de extrema complexidade social. A possibilidade de ação de qualquer identidade deve ser entendida em sentido relacional: uma identidade busca impor suas vontades na concorrência com outras, visando com isso universalizar seus conteúdos particulares. A complexidade do social, no entanto, impede necessariamente a completa universalização ou totalização desses conteúdos particulares, uma vez que tentativas de fechamento completo de sentidos sociais são empreitadas sempre incompletas e precárias. Mais: são, além de empreitadas incompletas e precárias, contingentes, uma vez que nada pode garantir que determinadas explicações ou efeitos de sentido possam ser capazes de serem universalizados necessariamente. Isso nos leva a concluir que, numa análise que tenha por base a Teoria do Discurso, não há como se constituir previamente sentidos sociais ou se levar em consideração identidades ou movimentos sociais totalmente constituídos com projetos políticos existentes "desde sempre" em direção a um objetivo preciso (teleológico).

Nesse contexto de sentidos sempre mal fechados e incompletos é que a noção de discurso possui sua centralidade. Dessa forma, identidades são vistas como discursos disputando sentidos no que Laclau e Mouffe (1985) denominam de campo da discursividade. Um discurso é, dessa forma, uma prática social significativa. $\mathrm{O}$ espaço social deve ser considerado como um espaço discursivo se ampliarmos a noção de discurso para aquilo que articula "todo o tipo de ligação entre palavras e ações, formando assim totalidades significativas" (Laclau 2000: 10). Em termos analíticos mais precisos, um discurso, ou uma totalidade estruturada relacional, é o resultado de uma prática articulatória que constitui e organiza relações sociais. A prática articulatória, por sua vez, consiste na articulação de elementos num sistema discursivo a partir de um ponto nodal que fixa parcialmente os sentidos desse sistema. A fixação de sentidos é necessariamente parcial tendo em vista as constantes suturas que o discurso sofre na relação com outros discursos concorrentes no campo da discursividade.

É importante ainda termos presente que a fixação de sentidos está limitada a estrutura discursiva pensada em termos sistêmicos. Para Laclau e Mouffe (1985), a produção de sentidos ocorre obrigatoriamente a partir da articulação de momentos no interior de um sistema discursivo, ou seja, a prática articulatória é uma prática autorreferenciada, pois toda a produção de sentidos de um sistema 
discursivo é interna e construída a partir de suas próprias estruturas. ${ }^{2}$ Isso quer dizer, por óbvio, que o que está além dos limites do sistema discursivo não produz qualquer sentido neste sistema. O que está além dos limites do discurso, na designação de Laclau e Mouffe, é elemento, ou seja, uma diferença que não está discursivamente articulada. Dessa forma, o funcionamento do sistema discursivo é assim visto por Laclau e Mouffe:

No contexto dessa discussão, chamaremos articulação qualquer prática que estabeleça uma relação entre elementos tal que suas identidades sejam modificadas como um resultado da prática articulatória. A totalidade estruturada resultante da prática articulatória chamaremos de discurso. As posições diferenciais, na medida em que elas apareçam articuladas num discurso, nós chamaremos momentos. Por contraste, chamaremos elemento qualquer diferença que não está discursivamente articulada. (1985: 105)

Assim, de acordo com os autores em questão, a articulação é uma prática que se estabelece entre elementos que, num primeiro momento, não estão articulados entre si. Podemos dizer, portanto, que no momento anterior ao da articulação, os elementos estão imersos numa lógica complexa, ou seja, estão dispersos, um em relação ao outro, de forma aleatória, no campo da discursividade. A prática articulatória agrega esses elementos transformando-os em momentos. Portanto, um elemento, quando ingressa na articulação e em relação a esta, deixa seu status de elemento e assume a condição de momento diferencial. A articulação entre esses momentos diferenciais resulta inexoravelmente na modificação de suas identidades, ou melhor, numa alteração semântica de seus conteúdos particulares anteriores ao ingresso na prática articulatória. O resultado da prática articulatória é o discurso.

O esforço que fizemos até aqui foi o de tentar apresentar sucintamente alguns elementos explicativos do funcionamento do sistema discursivo a partir da perspectiva da Teoria do Discurso. Tal esforço busca enfatizar que estabelecer uma análise de movimentos sociais tendo em vista esse projeto teórico deve levar em consideração um espaço social dominado por disputas entre discursos que visam hegemonizar seus conteúdos. Evidentemente que os recursos políticos estão distribuídos de forma desigual entre os mais diversos discursos concorrentes. Recursos

2 A questão da autorreferencialidade de um sistema discursivo não é tratada por Ernesto Laclau da forma direta como esta é vista por Niklas Luhmann. Antes é uma constatação que já realizamos quando, em outro momento, realizamos um exercício comparativo entre algumas categorias desses autores (Mendonça e Rodrigues 2002). 
políticos diferentes infere logicamente à idéia de que o poder político também está distribuído de forma desigual.

O poder, para os autores em questão, é constituidor de relações sociais. Dessa forma, conforme Mouffe (2000), todo consenso - no sentido da busca da eliminação da relação desigual de poder - conforme proposto por teóricos deliberacionistas como Rawls e Habermas, não passa de um resultado hegemônico sempre provisório. Mouffe ainda defende que a idéia de que as relações de poder possam ser dissolvidas através de um debate racional é uma ilusão teórico-prática.

$\mathrm{Na}$ base desta crítica, além das relações de poder como constituidoras do social, está a noção já aqui referida de que todas as relações sociais são constantemente suturadas pela precariedade e pela contingência. Assim, é impossível definirmos a priori o resultado de qualquer embate social, ou que força política poderá assumir papel de liderança num futuro próximo e por quanto tempo esta incerta liderança perdurará. As relações de poder, assim, devem ser analisadas in loco e como estamos tratando de relações entre identidades em embate, com racionalidades muitas vezes antagônicas, torna-se difícil definir uma racionalidade que abarque posições muitas vezes inconciliáveis. Assim, não há como se suprimir relações de poder e de conflito: estas são, aliás, garantias da pluralidade, da existência de diferenças sociais.

Tendo por "pano de fundo", portanto, as relações de poder como constitutivas do social, tomemos o sentido de agonismo, a partir do verbete agon (competição):

por agon se entende o debate judiciário e, em geral, a competição oratória. Este conjunto de conotações (competição submetida, diante de um público, a uma arbitragem segundo uma regra), dá o contexto da aparição, a partir da sofística, do diálogo filosófico (Auroux 1990: 52).

Como na passagem acima, o ponto fundamental da noção filosófica de agonismo, além da evidente idéia de competição ou de disputa, é a existência de regras que fazem com que os adversários partam sua luta de um ponto comum, de modo que a disputa não ocorra com o fim de destruir o oponente, mas pela legitimação de um discurso em detrimento de outro. O "debate judiciário", a "competição oratória" perante um público espectador, representam a competição agônica diante de regras previamente ajustadas e na presença de testemunhas que lhe dão legitimidade.

Foi Chantal Mouffe quem introduziu a noção de agonismo no âmbito da Teoria do Discurso. Tal apropriação foi importante no sentido da elaboração 
de uma noção que previsse disputas por poder político diferentes daquelas que a categoria de antagonismo prevê. Vejamos, a partir de Mouffe (2000), a diferença fundamental entre antagonismo e agonismo.

Numa relação antagônica entre dois elementos não existe possibilidade de se estabelecer medida comum entre eles: discursos antagônicos representam, assim, a luta entre inimigos. Já em relação ao agonismo, apesar da disputa entre diferentes formações discursivas, existe uma medida comum entre elas, um universal mínimo, que é o reconhecimento da legitimidade da existência do discurso concorrente. ${ }^{3}$ Além disso, em termos políticos, na relação agônica, a categoria de inimigo - presente na disputa antagônica - é substituída pela de adversário, uma vez que o espaço comum entre adversários reside justamente na aceitação da disputa política num espaço discursivo democrático pluralista. Não há, portanto, por que se falar em relação antagônica quando estamos diante de um Estado Democrático de Direito cujas regras são inicialmente partilhadas pelos grupos sociais. Aliás, esse é o projeto político defendido por Chantal Mouffe (2000): a transformação de relações antagônicas em agônicas e a superação da relação entre inimigos (antagonismo) para uma relação entre adversários (agonismo), já que as relações de poder são inerentes e constituidoras da política. Nas palavras de Mouffe:

Introduzir a categoria de 'adversário' requer complexificar a noção de antagonismo e distinguir duas diferentes formas nas quais ele pode emergir: antagonismo propriamente dito e agonismo. Antagonismo é a luta entre inimigos, enquanto que o agonismo é a luta entre adversários. Podemos, portanto, reformular nosso problema, pensando a partir de uma perspectiva de 'pluralismo agonístico', que o objetivo das políticas democráticas é transformar antagonismo em agonismo. (2000: 102-103)

Tendo os movimentos sociais a disputa agônica como princípio de atuação em suas lutas por reconhecimento, a democracia, como regime político, tende a se radicalizar. Não há como suprimir relações de poder entre discursos que dispõem de recursos desiguais e diferentes racionalidades. Não há, ainda,

3 Chantal Mouffe enfatiza a necessidade de se entender que a relação agônica representa a disputa entre adversários, na qual, ao contrário do antagonismo, não se discute a pertinência da existência dos mesmos: "O que caracteriza a democracia pluralista (...) é a instauração da distinção entre as categorias de 'inimigo' e de 'adversário'. Isso significa que no interior da comunidade política não se verá no oponente um inimigo a abater, mas um adversário de legítima existência ao qual se deve tolerar. Combatem com vigor suas idéias, contudo jamais se questionará o direito de defendêlas" (Mouffe 2002: 01). 
como construir consensos permanentes num espectro político dominado pela indecidibilidade e pela contingência. $\mathrm{O}$ espaço democrático é necessariamente um espaço de lutas. O princípio agônico da possibilidade de identidades plurais enunciarem suas demandas é fundamental para o avanço de políticas sociais de inclusão de diferenças. Contudo, a luta agônica precisa ser constante, pois mesmo após a conquista do direito, a partir da publicação de uma lei, este ainda pode estar ameaçado, como vimos, pela ineficácia da aplicação da norma jurídica.

\section{Considerações finais: praticando o agonismo respeitando a pluralidade}

Se a lei pode frustrar as expectativas de movimentos sociais, uma vez que, mesmo com sua existência, não se pode garantir o real adimplemento de um direito, que devem fazer os movimentos sociais? Em nossa perspectiva, não há outra alternativa a não ser manter viva a luta: a disputa agônica.

Contemporaneamente, na base da idéia de agonismo, temos a democracia representativa como "universal mínimo" entre os múltiplos grupos sociais sempre em disputa por reconhecimento. Pensar o regime democrático, nessa perspectiva, do nosso ponto de vista, requer fazermos duas considerações sobre como encarar a democracia.

A primeira forma de se encarar a democracia pressupõe a aceitação do pluralismo, aqui entendido como a garantia de que movimentos sociais, identidades, grupos sociais tenham a possibilidade de enunciar seus discursos e que, como tais, sejam, ao menos, aceitos como legítimos de serem enunciados. Já a segunda forma de encararmos a democracia deve levar em consideração este regime como um conjunto de normas procedimentais que visem garantir decisões públicas fundamentadas no princípio da vontade da maioria. Asseguradas a pluralidade de enunciação de discursos, bem como o estabelecimento de regras claras de como enunciá-los, podemos anunciar nossas considerações finais acerca do agonismo como princípio de ação de movimentos sociais.

Nesse sentido, vimos, ao longo deste artigo, que a norma jurídica, ao invés de ser uma efetiva garantia de direitos, pode servir como um mero instrumento de conformação de movimentos sociais, gerando, assim, possíveis des- 
mobilizações desses movimentos quando do não adimplemento da lei. Uma legislação ineficaz é letra morta em termos de avanços efetivos de reconhecimento social para movimentos identitários.

Dessa forma, é mister que as lutas dos movimentos sociais sejam constantes, mesmo após a vigência da lei que formalmente lhes confere direitos. Tais lutas devem necessariamente apontar para duas questões centrais: a) a mobilização interna da organização social para mantê-la unida e atuante para que seus propósitos políticos consigam ir além da simples publicação da norma jurídica e; b) o estabelecimento de estratégias de fiscalização tendo em vista um real implemento das demandas sociais transformadas em lei. Em outras palavras, é importante a manutenção da disputa agônica, tendo em vista um cada vez maior reconhecimento do pluralismo e das regras do Estado Democrático de Direito como garantias da enunciação de discursos que condenem a exclusão.

O princípio agônico de lutas constantes, respeitando-se, contudo, regras partilhadas pelos agentes em disputa, permite a emergência e a garantia de enunciação de discursos identitários num universo democrático-pluralista, desde que tais identidades respeitem tais regras, seus universais mínimos.

Radicalizar a democracia significa ampliar a abrangência de direitos a um número cada vez maior de identidades. De uma parte, não há radicalização possível sem lutas, sem disputas. De outra parte, não há também radicalização do processo democrático sem respeito às diferenças e às regras do jogo.

\section{Referências bibliográficas}

Auroux, Sylvain (1990). Les notions philosophiques dictionnaire - Tome 1: Philosophie Occidentale. In: André Jacob (org.). Encyclopédie philosophique universelle. Paris: Presses Universitaires de France.

Laclau, Ernesto (2000). La guerre des identités: grammaire de l'émancipation. Paris: La Découverte.

— ; Mouffe, Chantal (1985). Hegemony \& socialist strategy: towards a radical democratic politics. London: Verso.

Mendonça, Daniel de; Rodrigues Junior, Léo (2002). Algumas congruências, a partir da perspectiva do novo pensamento sistêmico, no âmbito da teoria do discurso de Ernesto Laclau e da teoria dos sistemas sociais de Niklas Luhmann. In: Léo Rodrigues Juni- 
or (org.). Pós-fundacionalismo: reflexões teórico-sistêmicas em Laclau \& Luhmann. Porto Alegre: Ufrgs/Pucrs (no prelo).

Mouffe, Chantal (2000). The democratic paradox. London: Verso.

—. La nueva lucha por el poder (2002). Internet: $<$ http://www.politica.com.ar/Filosofia_politica/La_nueva_lucha_por_el_poder_Mouffe.htm $>-$ último acesso: 25 jan. 2002 . 